\title{
AKTIVITAS DAN RESPON SISWA MELALUI MODEL PEMBELAJARAN WITHIN-SOLUTION POSING
}

\author{
Utin Desy Susiaty \\ Program Studi Pendidikan Matematika, Fakultas Pendidikan, MIPATEK, IKIP PGRI Pontianak \\ d3or4f4ty4@gmail.com
}

\begin{abstract}
The purpose of this study was to describe the activities and responses of students through the in-solution posing learning model. This research uses quantitative approach with descriptive method. The population in this study is the students of class VII MTs Negeri 2 Pontianak academic year 2007/2008 who studied the material of comparative value and turned the value. The result of the research shows that students of Grade VII MTs Negeri 2 Pontianak are active in learning with within-solution posing and VII students of MTs Negeri 2 Pontianak give positive response to learning with within-solution posing.
\end{abstract}

Keywords: activities, response, within -solution posing

\section{PENDAHULUAN}

Saat ini materi pelajaran matematika masih dianggap sulit dibandingkan dengan materi pelajaran yang lain. Hal ini dimungkinkan karena matematika merupakan disiplin ilmu yang bersifat abstrak. Salah satu materi matematika yang dianggap sulit oleh siswa adalah materi yang berkaitan dengan soal cerita. Kesulitan siswa tersebut dapat dilihat dari kesalahankesalahan yang dilakukan saat menyelesaikan soal cerita.

Hasil wawancara dengan salah satu guru bidang studi matematika MTs Negeri 2 Pontianak diperoleh informasi bahwa masih banyak siswa MTs Negeri 2 Pontianak mengalami kesulitan dalam menyelesaikan soal cerita yang berkaitan dengan materi perbandingan senilai dan berbalik nilai. Kesulitan ini terjadi pada hampir separuh siswa dalam tiap kelas di setiap tahun pelajaran.

Selain informasi mengenai hasil belajar siswa, peneliti juga melakukan observasi untuk melihat langsung proses pembelajaran yang dilaksanakan guru di dalam kelas. Hasil observasi memperlihatkan kegiatan pembelajaran dan cara guru menjelaskan konsep perbandingan sebagai berikut : 1) guru memulai kegiatan pembelajaran dengan menjelaskan materi mengenai perbandingan. Guru juga mengingatkan siswa mengenai konsep perbandingan; 2) guru mulai menjelaskan konsep perbandingan dengan cara memberikan contoh soal di papan tulis.

Pembelajaran (Sanjaya, 2012) didesain untuk membelajarkan siswa, artinya siswa ditempatkan sebagai subjek belajar. Dengan kata lain, pembelajaran lebih berorientasi pada aktivitas siswa untuk memperoleh hasil belajar berupa perpaduan antara aspek kognitif, afektif, dan psikomotor secara proposional. Keaktifan siswa ada yang secara langsung dapat diamati dan ada yang tidak dapat diamamti secara langsung, seperti mengerjakan tugas, berdiskusi, dan mengumpulkan data. Kadar keaktifan siswa tidak hanya ditentukan oleh aktivitas fisik semata, tetapi juga oleh aktivitas nonfisik seperti mental, intelektual, dan emosional. Oleh sebab itu, 
aktif atau tidaknya siswa dalam belajar hanya siswa sendiri yang mengetahui secara pasti.

Pembelajaran yang dilakukan selama ini lebih terpusat kepada guru. Siswa hanya mendengar dan menyambung pernyataan atau menjawab pertanyaan guru dalam pembelajaran. Guru hanya membimbing siswa untuk sampai pada tahap "ingat", dengan kata lain siswa hanya mengingat atau menghafal cara-cara penyelesaian yang dilakukan guru dalam menyelesaikan soal cerita tanpa siswa memahami sepenuhnya. Hal ini dapat menimbulkan masalah bagi siswa setiap kali menemukan soal cerita, karena siswa bisa saja lupa pada cara-cara penyelesaian yang telah diajarkan. Ini menunjukkan perlunya siswa bertindak aktif dalam suatu pembelajaran agar bisa memahami hal-hal yang dipelajari.

Hal tersebut menunjukkan bahwa pentingnya suatu aktivitas yang dilakukan oleh siswa untuk mencapai hasil belajar yang maksimal. Berbuat untuk merubah tingkah laku melalui perbuatan adalah prinsip belajar. Ada atau tidaknya belajar dicerminkan dari ada atau tidaknya aktivitas. Tanpa ada aktivitas, belajar tidak mungkin terjadi. Sehingga dalam interaksi belajar-mengajar aktivitas merupakan prinsip yang penting (Sardiman, 2011).

Penggunaan metode, pendekatan belajar mengajar dan orientasi belajar menyebabkan aktivitas belajar setiap siswa berbeda-beda. Ketidaksamaan aktivitas belajar siswa melahirkan kadar aktivitas belajar yang bergerak dari aktivitas belajar yang rendah sampai aktivitas belajar yang tinggi (Djamarah, 2010).

Salah satu upaya yang dapat digunakan agar siswa bertindak aktif dalam suatu pembelajaran adalah menerapkan pembelajaran within-solution posing, karena terdapat pengalihan tanggung jawab dalam membuat kalimat pertanyaan matematika dari guru ke siswa. Adanya pengalihan tanggung jawab ini dapat mendorong siswa menjadi aktif dalam proses pembelajaran matematika.

Hal ini sesuai dengan yang diungkapkan oleh Silver et al., (1996:294) mendefinisikan bahwa problem posing ialah perumusan soal yang berkaitan dengan syarat-syarat pada soal yang telah dipecahkan, dalam rangka mencari alternatif pemecahan masalah atau alternatif soal yang masih relevan. Xia et al., (2008:158) mendefinisikan : "Problem posing is the core of Situated Creation and Problem-based Instruction (SCPBI) and improving students, abilities to pose". Bonotto (2010:21) mendefinisikan : "Problem posing could occur during problem solving when the individual intentionally changes goals while in the process of solving the problem".

Lowrie (2002:89) mendefinisikan : "Problemposing contexts should encourage students to look beyond the mathematical content they typically focus on and consider, with increased sophistication, problem representation and strategy selection". Silver (dalam Pittalis, 2004:51) memberikan istilah problem posing diaplikasikan pada tiga bentuk aktivitas kognitif matematika yang berbeda, yaitu sebagai berikut: 1) problem posing sebelum penyelesaian (pre-solution posing) berarti siswa membuat pertanyaan dari situasi yang disediakan seperti cerita, gambar atau bilangan; 2) problem posing selama penyelesaian (within-solution posing) berarti siswa merumuskan kembali pertanyaan-pertanyaan yang dengan beberapa perubahan agar lebih sederhana dan dapat dikuasai; 3) problem posing setelah penyelesaian (post-solution posing) berarti siswa memodifikasi soal yang sudah diselesaikan untuk membuat soal baru. Dalam penelitian ini problem posing didefinisikan perumusan kembali pertanyaanpertanyaan yang masih relevan dengan soal yang diberikan sebagai langkah dalam penyelesaian soal tersebut (within-solution posing). 


\section{METODE PENELITIAN}

Penelitian ini menggunakan pendekatan kuantitatif dengan metode deskriptif. Peneliti memilih satu kelas secara Cluster Random Sampling untuk dijadikan sampel dalam penelitian. Satu kelas tersebut akan diberikan pembelajaran within-solution posing, yang kemudian disebut kelompok eksperimen. Selama pembelajaran observer mengamati kegiatan siswa selama pembelajaran dengan within-solution posing. Setelah selesai pemberian tindakan pada kelas tersebut, selanjutnya akan diberikan angket respon terhadap pembelajaran dengan within-solution posing. Penelitian ini dilaksanakan pada tahun ajaran 2007/2008 semester ganjil atau bersamaan dengan pelaksanaan materi perbandingan senilai dan berbalik nilai pada MTs Negeri 2 Pontianak.

Populasi dalam penelitian ini adalah seluruh siswa kelas VII MTs Negeri 2 Pontianak tahun ajaran 2007/2008 yang akan mempelajari materi perbandingan senilai dan berbalik nilai yaitu kelas VII A, VII B, VII C, VII D, dan VII E. Sampel yang akan dipilih hanya 1 kelas dari 5 kelas yang ada. Sampel dipilih dengan menggunakan teknik Cluster Random Sampling. Sebelum dilakukan pemilihan sampel secara acak, semua populasi akan diuji homogenitasnya.

Fokus dalam penelitian ini adalah analisis aktivitas dan respon siswa melalui penerapan model pembelajaran wthin-solution posing. Oleh karena itu, teknik pengumpul data yang digunakan adalah teknik observasi dan teknik komunikasi tak langsung dengan alat pengumpul data adalah lembar observasi dan angket respon siswa. Lembar observasi digunakan untuk mengamati aktivitas siswa selama pembelajaran berlangsung. Lembar observasi yang digunakan memuat beberapa kategori pengamatan terhadap aktivitas belajar siswa yang disesuaikan dengan RPP. Adapun kategori pengamatan aktivitas siswa, yaitu : 1) mendengarkan/memperhatikan penjelasan dari guru; 2) memberikan tanggapan; 3) menerima soal- soal yang latihan yang diberikan oleh guru dan mempelajarinya; 4) membuat pertanyaan-pertanyaan yang masih relevan dengan soal yang diberikan; 5) menyelesaikan soal; 6) bertanya kepada guru tentang kesulitan yang dihadapi dalam membuat soal; 7) membuat kesimpulan; 8) perilaku yang tidak sesuai dengan kegiatan pembelajaran.

Untuk mengetahui respon siswa setelah diberikan pembelajaran within-solution posing, digunakanlah angket respon siswa. Angket yang digunakan adalah angket tertutup. Instrumen ini digunakan untuk memperoleh data mengenai pendapat atau komentar siswa terhadap komponen pembelajaran yang meliputi materi pembelajaran, bahan ajar, cara belajar dan cara guru mengajar. Angket respon diberikan setelah siswa diberikan pembelajaran dengan within-solution posing.

\section{HASIL PENELITIAN DAN PEMBAHASAN}

Pada saat pembelajaran berlangsung, siswa diamati oleh dua orang pengamat yang berada di sisi samping kelas. Pengamat ini bertugas untuk mengamati tingkah laku siswa selama pembelajaran berlangsung dan mencatatnya dalam lembar pengamatan aktivitas siswa.

Pengamatan tidak dilakukan terhadap semua siswa. Hal ini dikarenakan untuk mengantisipasi adanya kemungkinan siswa yang tidak hadir pada saat penelitian berlangsung. Oleh karena itu pengamatan dilakukan terhadap 6 orang siswa. Posisi siswa yang diamati serta pengamat dapat dilihat pada Gambar 1 berikut. 


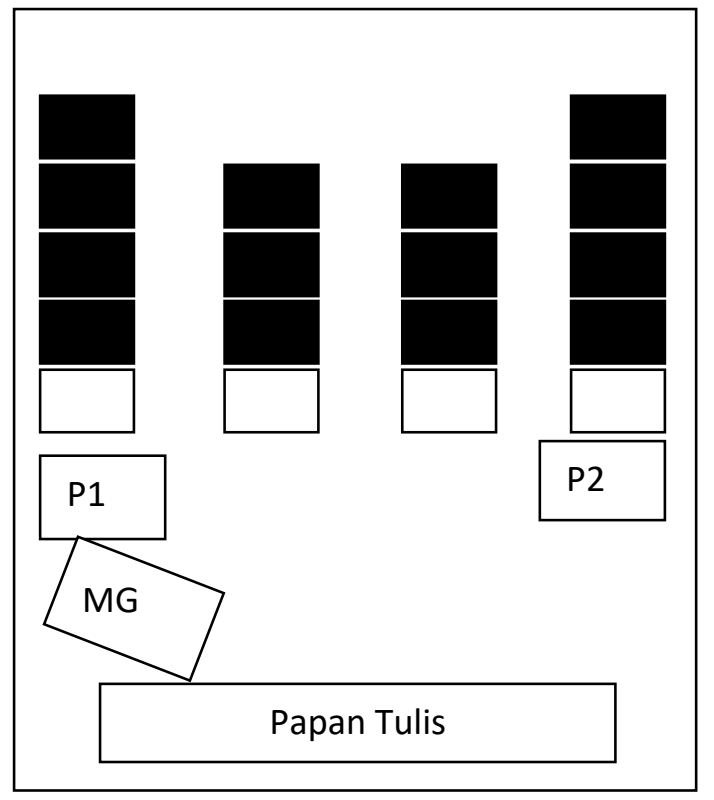

Gambar 1. Posisi Siswa Dan Pengamat

Keterangan :

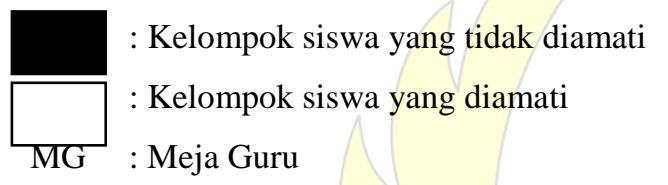

Angket diberikan kepada siswa dengan tujuan untuk mengetahui seberapa besar respon siswa terhadap pembelajaran dengan within-solution posing. Angket ini diberikan kepada siswa setelah pembelajaran. Berikut hasil skor jawaban dari angket respon siswa dan perhitungan tingkat persetujuannya terhadap pembelajaran :

Tabel 1. Distribusi Respon Siswa

\begin{tabular}{|c|c|c|c|c|c|c|}
\hline \multirow{2}{*}{$\begin{array}{c}\text { No } \\
\text { Pernyataan }\end{array}$} & \multicolumn{5}{|c|}{ Jumlah Tanggapan } & \multirow{2}{*}{$\begin{array}{c}\text { Jumlah } \\
\text { Skor }\end{array}$} \\
\hline & SS & $\mathbf{S}$ & $\mathbf{R}$ & TS & STS & \\
\hline 1. & 6 & 24 & 6 & 0 & 0 & 144 \\
\hline 2. & 1 & 3 & 8 & 19 & 5 & 132 \\
\hline 3. & 1 & 5 & 7 & 19 & 4 & 128 \\
\hline 4. & 12 & 11 & 11 & 2 & 0 & 141 \\
\hline 5. & 10 & 17 & 8 & 1 & 0 & 144 \\
\hline 6. & 5 & 9 & 8 & 11 & 3 & 106 \\
\hline 7. & 19 & 10 & 1 & 6 & 0 & 150 \\
\hline 8. & 3 & 4 & 11 & 14 & 4 & 120 \\
\hline 9. & 21 & 15 & 0 & 0 & 0 & 165 \\
\hline 10. & 12 & 18 & 5 & 1 & 0 & 149 \\
\hline
\end{tabular}

\begin{tabular}{ccccccc}
\hline \multirow{2}{*}{$\begin{array}{c}\text { No } \\
\text { Pernyataan }\end{array}$} & \multicolumn{5}{c}{ Jumlah Tanggapan } & Jumlah \\
\cline { 2 - 6 } & SS & S & R & TS & STS & Skor \\
\hline 11. & 0 & 2 & 5 & 16 & 13 & 148 \\
\hline 12. & 5 & 17 & 14 & 0 & 0 & 135 \\
\hline 13. & 16 & 15 & 3 & 2 & 0 & 153 \\
\hline 14. & 7 & 16 & 13 & 0 & 0 & 138 \\
\hline 15. & 11 & 18 & 7 & 0 & 0 & 148 \\
\hline \multicolumn{6}{c}{ Jumlah } \\
\hline \multicolumn{7}{c}{}
\end{tabular}

Berdasarkan table 1 diperoleh tingkat persetujuan terhadap pembelajaran within-solution posing sebesar $77,81 \%$. Data dari hasil angket respon siswa dikelompokkkan menjadi dua yakni untuk pernyataan positif dan pernyataan negatif. Berikut data jumlah kategori pilihan angket respon siswa.

Tabel 2. Data Jumlah Kategori Pilihan Angket Respon Siswa untuk Pernyataan Positif

\begin{tabular}{ccccccc}
\hline \multirow{2}{*}{ No } & No & \multicolumn{6}{c}{ Jumlah Tanggapan } \\
\cline { 3 - 7 } & Pernyataan & SS & S & R & TS & STS \\
\hline 1. & 1 & 6 & 24 & 6 & 0 & 0 \\
\hline 2. & 4 & 12 & 11 & 11 & 2 & 0 \\
\hline 3. & 5 & 10 & 17 & 8 & 1 & 0 \\
\hline 4. & 7 & 19 & 10 & 1 & 6 & 0 \\
\hline 5. & 9 & 21 & 15 & 0 & 0 & 0 \\
\hline 6. & 10 & 12 & 18 & 5 & 1 & 0 \\
\hline 7. & 12 & 5 & 17 & 14 & 0 & 0 \\
\hline 8. & 13 & 16 & 15 & 3 & 2 & 0 \\
\hline 9. & 14 & 7 & 16 & 13 & 0 & 0 \\
\hline 10. & 15 & 11 & 18 & 7 & 0 & 0 \\
\hline & & 119 & 161 & 68 & 12 & 0 \\
\hline
\end{tabular}

\section{Berdasarkan table 2 diperoleh persentase} angket respon siswa untuk pernyataan positif dan kemudian membandingkan persentase pada kategori sangat setuju dan setuju dengan persentase pada kategori sangat tidak setuju, tidak setuju dan raguragu.

Jika

$P(S S)+P(S)>P(S T S)+P(T S)+P(R)$ maka respon siswa dikatakan positif dan pada keadaan lain 
respon siswa dikatakan negatif. Karena $P(S S)+P(S)>P(S T S)+P(T S)+P(R) \quad$ atau $(77,78 \%>22,22 \%)$ maka respon siswa untuk pernyataan positif terhadap pembelajaran dengan within-solution posing adalah positif.

Tabel 3. Data Jumlah Kategori Pilihan Angket Respon Siswa untuk Pernyataan Negatif

\begin{tabular}{|c|c|c|c|c|c|c|}
\hline \multirow{2}{*}{ No } & \multirow{2}{*}{$\begin{array}{c}\text { No } \\
\text { Pernyataan }\end{array}$} & \multicolumn{5}{|c|}{ Jumlah Tanggapan } \\
\hline & & SS & $\mathbf{S}$ & $\mathbf{R}$ & TS & STS \\
\hline 1. & 2 & 1 & 3 & 8 & 19 & 5 \\
\hline 2. & 3 & 1 & 5 & 7 & 19 & 4 \\
\hline 3. & 6 & 5 & 9 & 8 & 11 & 3 \\
\hline 4. & 8 & 3 & 4 & 11 & 14 & 4 \\
\hline 5. & 11 & 0 & 2 & 5 & 16 & 13 \\
\hline & Jumlah & 10 & 23 & 39 & 79 & 29 \\
\hline
\end{tabular}

Tabel 4. Perhitungan Aktivitas Siswa pada Pembelajaran

\begin{tabular}{ccccc} 
Tahap & & & \multicolumn{2}{c}{ Persentase } \\
\cline { 4 - 5 } $\begin{array}{c}\text { Pembelajaran } \\
\text { Within-Solution Posing }\end{array}$ & Siswa Aktif & Siswa Pasif & Aktif & Pasif \\
\hline Pendahuluan & 10 & 2 & 8,33 & 1,67 \\
\hline Pengembangan & 24 & 6 & 20 & 5 \\
\hline Menerima & 23 & 1 & 19,17 & 0,83 \\
\hline Menantang & 30 & 0 & 25 & 0 \\
\hline Melihat Kembali & 15 & 3 & 12,5 & 2,5 \\
\hline Penutup & 4 & 2 & 3,33 & 1,67 \\
\hline Jumlah & 106 & 14 & 88,33 & 11,67 \\
\hline
\end{tabular}

Berdasarkan hasil perhitungan di atas, Masih terdapatnya kelemahan dalam penelitian persentase siswa aktif lebih besar dari persentase siswa pasif. Sehingga dapat disimpulkan siswa aktif dalam pembelajaran dengan within-solution posing.

\section{SIMPULAN DAN SARAN}

Berdasarkan hasil penelitian dan analisis statistik yang diperoleh dapat disimpulkan bahwa siswa kelas VII MTs Negeri 2 Pontianak aktif dalam pembelajaran dengan within-solution posing dan siswa kelas VII MTs Negeri 2 Pontianak memberikan respon positif terhadap pembelajaran dengan within-solution posing.
Berdasarkan table 3 diperoleh persentase angket respon siswa untuk pernyataan negative dan kemudian membandingkan persentase pada kategori sangat tidak setuju dan tidak setuju dengan persentase pada kategori sangat setuju, setuju dan ragu-ragu. Jika $P(S T S)+P(T S)>P(R)+P(S)+P(S S)$ maka respon siswa dikatakan positif dan pada keadaan lain respon siswa dikatakan negatif. Karena $(60,00 \%>40,00 \%)$ maka respon siswa untuk pernyataan negatif terhadap pembelajaran dengan within-solution posing adalah positif.

Hasil pengamatan aktivitas siswa selama kegiatan pembelajaran dengan within-solution posing dapat dilihat pada tabel berikut. $P(S T S)+P(T S)>P(R)+P(S)+P(S S)$ atau 


\section{DAFTAR PUSTAKA}

Bonotto, C. 2010. "Engaging Students in Mathematical Modelling and Problem Posing Activities". Journal of Mathematical Modelling and Application. Vol. 1, no. 3, hlm. 18-32.

Djamarah, Syaiful Bahri. 2010. Guru dan Anak Didik dalam Interaksi Edukatif. Jakarta : Rineka Cipta.

Lowrie, T. 2002. "Young Children Posing Problems : The Influence of Teacher Intervention on the Type of Problems Children Pose". Mathematics Education Research Journal. Vol. 14, no. 2, hlm. 87-98.

Pittalis, M. 2004. A Structural Model For Problem Posing, hlm. 49-56. dalam Christou, C, Mousoulides, N,. \& Pitta-Pantazi, D (edt.). Proceedings of the 28th Conference of the International Group for the Psychology of Mathematics
Education. Vol. 4. University of Cyprus, Department of Education.

Sanjaya, Wina. 2012. Strategi Pembelajaran Berorientasi Standar Proses Pendidikan. Jakarta : Kencana Prenada Media Group.

Sardiman, A.M. 2011. Interaksi dan Motivasi Belajar Mengajar. Jakarta: Raja Grafindo Persada.

Silver, E.A,. Downs, J.M,. Leung, S.S,. \& Kenney, P.A. 1996. "Posing Mathematical Problems: An exploratory Study". Journal For Research In Mathematics Education. Vol. 27, no.3, hlm. 293-309.

Xia, X,. Lu, C,. \& Wang, B. 2008. "Research on Mathematics Instruction Experiment Based Problem Posing". Journal of Mathematics Education. Vol. 1, no.1, hlm. 153-163. 